\title{
Use of Waist to Height Ratio in assessing metabolic derangements among normal and overweight/obese 5-15 year old individuals
}

\author{
V.P. Wickramasinghe ${ }^{1}$, C. Arambepola ${ }^{2}$, P. Bandara ${ }^{1}$, M. Abeysekera ${ }^{1}$, S. Kuruppu ${ }^{1}$, P. Dilshan ${ }^{1}$, \\ B.S. Dissanayake ${ }^{1}$ \\ 1Department of Paediatrics, Faculty of Medicine, University of Colombo, Sri Lanka \\ ${ }^{2}$ Department of Community Medicine, Faculty of Medicine, University of Colombo, Sri Lanka
}

A R T I C L E I N F O

Article history:

Submission 21.02.2017

Acceptance 20.05.2017

Available online

\section{DOI:}

http://doi.org/10.4038/cjms.v54i1.4813

Keywords:

Sri Lankan children

Childhood obesity

Metabolic syndrome

Waist to height ratio

\begin{abstract}
Background and objectives

Although Body Mass Index (BMI) is used to assess obesity, it does not always relate to central obesity, the main metabolic risk factor. Waist to height ratio (WHtR) is a simple index of central obesity. This study assessed its usefulness in detecting metabolic derangements in 5-15 year old Sri Lankan children.
\end{abstract}

\section{Method}

A cross sectional descriptive study on healthy 5-15 year old children was conducted in Colombo district. Height, weight and Waist Circumference (WC) were measured. WHtR and BMI (classified by WHO cutoff $>2 \mathrm{SD}$ ) were calculated. Obesity was defined by percentage fat mass measured by Bio Electrical Impedance Assay (BIA - InBody-230 BIA machine) and validated against Sri Lanka body composition equations.

After a 12-hour overnight fast, blood was drawn for Fasting Blood Glucose (FBG) and lipid profile. Standard Oral Glucose Tolerance Test (OGTT) was performed to obtain Random Blood Glucose (RBG) at 2 hours.

Metabolic Derangements (MetD) were defined as; WC for age $>90^{\text {th }}$ centile (UK standards); FBG>100mg/dl or RBG>140 mg/dl; HDLcholesterol $<40 \mathrm{mg} / \mathrm{dl}$; triglyceride $>150 \mathrm{mg} / \mathrm{dl}$; and systolic or diastolic blood pressure $>+2 \mathrm{SD}$ for age (UK standards). Metabolic Syndrome (MetS) was diagnosed by high WC plus $\geq 2$ other MetD. ROC curves were drawn to determine the optimal WHtR value that predicts MetS as well as $\geq 2$ MetD. Using these cutoffs, WHtR was also validated against obesity determined by $\%$ fat mass.

\section{Results}

A total of 920 children (547 boys) were studied: $16.6 \%$ were obese/ overweight and $55.6 \%$ had normal BMI. Close to $14 \%$ had central obesity. Those with normal BMI but having central obesity had higher total cholesterol and triglyceride levels, but were not statistically significant. WHtR detected more cases with abnormal cholesterol and HDL than BMI, but detection of cases with high triglycerides was similar to BMI.

WHtR to detect MetS was 0.51 (sensitivity-1.00; specificity-0.83) in boys and 0.49 (sensitivity-0.83; specificity-0.83) in girls. To detect $\geq 2$ MetD, WHtR was 0.42 (sensitivity-0.6; specificity-0.62) in boys and 0.45 (sensitivity-0.62; specificity-0.62) in girls.

\section{Conclusions}

WHtR is valid in detecting metabolic derangements in this group of Sri Lankan children. The cut off values (0.5) described to detect MetS in this group of children is similar to the value described in the literature. A cutoff value of 0.45 would detect at least two MetD, thus enabling early detection of obesity related metabolic morbidity. 


\section{BACKGROUND}

Non communicable diseases (NCD) such as diabetes mellitus and cardiovascular disease are increasing all over the world with its onset occurring at a younger age.

Although genetically predisposed, lifestyle changes have resulted in an exponential rise in obesity, both childhood and adulthood. This is associated with metabolic derangements such as dysglycaemia, dyslipidaemia and hypertension, and thereby directly contributing to the rise in NCD. In particular, early onset central obesity is identified to predispose one to such metabolic derangements. Therefore, early detection of those factors either individually or collectively as Metabolic Syndrome (MetS) is of paramount importance in order to control and prevent NCD related morbidity. However, it is not practical to periodically assess these in blood due to discomfort as well as cost, but an effective and practical surrogate marker would be of more use.

Obesity related Metabolic Derangements (MetD) have been reported not only in adults but also in children in Sri Lanka especially with the rise in incidence of childhood obesity [1]. This highlights the importance of having surrogate markers for early detection of abnormal metabolic profiles using non-invasive methods. Several anthropometric measures such as Body Mass Index (BMI), Waist Circumference (WC) and Waist to Hip Ratio (WHR) have been used as early predictors of the risk [2]. However, the sensitivity of the currently adopted cutoff values of these measures is not similar, thus posing the question of the validity of a single cutoff value universally [3]. Furthermore, anthropometric measures have shown poor detection of MetD [4] and the current BMI cutoff has been less sensitive in detecting obesity as well as MetD in Sri Lankan children [3, 4]. A major drawback of BMI is that it does not distinguish between Fat Mass (FM) and Fat Free Mass (FFM) nor does it show the pattern of fat distribution as central or peripheral, of which the latter is more associated with MetD [2].

WC is a better predictor of MetS, but cutoff values need revision [3]. WHR has been a poor predictor of abnormal metabolic derangements in Sri Lankan children. In contrast, Waist to Height Ratio (WHtR) has gained popularity as it is shown to be associated with the development of type 2 diabetes mellitus (T2DM), ischaemic heart disease (IHD) and cardiovascular disease (CVD) in adults [5]. Although the intra-abdominal fat in children is relatively low, WHtR has been able to predict CVD risk among children [2].

WHtR is a simple and effective anthropometric index and has shown to be useful in identifying obesity associated metabolic risks among Sri Lankan adults [5]. Framingham Study used the waist-to-height ratio for the first time [6] and since then, studies have shown that WHtR has a stronger association with CVD risk factors than BMI in both children [2] and adults [7].

WHtR is simple to calculate and as it does not have an association with age, a single cutoff value could be used across all ages and sexes [8] unlike BMI, which changes with age and sex when using standard deviation or centiles [9].

As it seems that conventional anthropometric methods and their cutoff's are not sensitive in detecting childhood obesity and MetD early in the disease process, this study was designed to assess the validity of WHtR in detecting MetD in 5-15 year old selected group of Sri Lankan children and the relationship of WHtR with other obesity related indices.

\section{METHODS}

A cross-sectional descriptive study was carried out among 5-15 year old apparently healthy Sri Lankan children living in Colombo; the most urban district in Sri Lanka. Sample was selected using a twostage, probability proportionate to size, clustersampling technique to recruit a minimum sample size of 790 children, so as to ensure an expected proportion of children with obesity of $2 \%$; level of precision of 0.01 ; confidence interval of 0.05 ; and a non-repose rate of $5 \%$. During the first stage of sampling, 15 schools were selected from a recently updated list of secondary schools in the district of Colombo, with a probability proportionate to the size of student population in each school. During 
stage two, one class each was selected from Grades 1-4; Grades 5-7; and Grades 8-10 using the lists of classes (that have at least 30 students) in each selected school. The entire class was considered as a cluster and sampled.

Students with any illness or on any medication were excluded. After informing the eligible students and their parents about the procedure, written consent from parents and assent from children above 10 years were obtained. Ethics review committees of the Faculty of Medicine, University of Colombo and Lady Ridgeway Hospital for Children approved the study.

Five medical graduates who were trained and supervised by VPW carried out all measurements.

\section{Assessment of anthropometric indices}

Height, weight, WC and Hip Circumference (HC) were measured in all participants using a standard protocol [10]. BMI [weight $(\mathrm{kg}) /$ height $\left.(\mathrm{m})^{2}\right]$, WHR $[\mathrm{WC}(\mathrm{cm}) / \mathrm{HC}(\mathrm{cm}))]$ and $\mathrm{WHtR}[\mathrm{WC}(\mathrm{cm}) /$ Height $(\mathrm{cm})]$ were calculated. Based on BMI for age index and WHO 2007 growth standards (11), participants were categorized as obese $(>+2 \mathrm{SD})$, overweight (+1SD to $+2 \mathrm{SD}$ and wasted $(<-2 \mathrm{SD})$.

\section{Assessment of obesity}

Obesity was assessed using Fat Mass (FM) measured using Bio Electrical Impedance Assay (BIA - InBody-230 BIA machine), which has been validated against Sri Lanka body composition equations [12]. Percentage FM cutoff values used to diagnose obesity was $28.6 \%$ for boys and $33.7 \%$ for girls [12].

\section{Assessment of metabolic derangements}

Blood pressure was measured in the seated position using a mercury sphygmomanometer after a 10minute rest. The first and fifth Korotkoff sounds were used to represent systolic (SBP) and diastolic (DBP) blood pressure, respectively.

Blood was drawn after a 12-hour overnight fast for Fasting Blood Glucose (FBG) and lipid profile. Oral glucose tolerance test (OGTT) was performed after giving to drink anhydrous glucose $1.75 \mathrm{~g} / \mathrm{kg}$ per body weight to a maximum of $75 \mathrm{~g}$ and blood drawn two hours later for random blood glucose (RBG) by an experienced nursing officer.

Blood glucose, total cholesterol, triglyceride and HDL cholesterol were quantitatively assessed using spectrophotometer (BioSystems ${ }^{\circledR}$ ). Blood glucose (both FBG and RBG) was assessed by enzymatic spectrophotometric method using glucose oxidase and peroxidase enzymes. Cholesterol ester molecule was cleaved using cholesterol oxidase and peroxidase enzymes, and enzymatic cleavage of triglyceride was done using glycerol phosphate oxidase and peroxidase enzymes. HDL-cholesterol was measured using enzymatic spectrophotometry with enzymatic analysis using cholesterol esterase, cholesterol oxidase and peroxidase.

\section{Definitions used in the study}

MetD were identified as: WC for age >+2SD centile of UK standard [13]; abnormal glucose homeostasis if FBG $>5.6 \mathrm{mmol} / \mathrm{L}$ or 2 hour OGTT (RBG) value $>7.8 \mathrm{mmol} / \mathrm{L}$; HDL $<1.03 \mathrm{mmol} / \mathrm{L}$; $\mathrm{TG} \geq 1.7 \mathrm{mmol} / \mathrm{L}$ [14]; and blood pressure $>+2 \mathrm{SD}$ for age for both SBP and DBP of UK standards [15]. This cutoff value for SBP and DBP was chosen instead of the cutoff values given by International Diabetes Federation (IDF) definition $(130 / 85 \mathrm{mmHg})$, which was suitable only for the tallest 15 year old children, thus leading to an under estimation of hypertension.

MetS was diagnosed by having $\geq 2$ metabolic derangements in addition to having high WC.

\section{Data analysis}

Data were entered and analyzed using SPSS (version 20). Data were summarized using mean and standard deviation (SD) for quantitative data and proportions for categorical data. Receiver operator characteristic (ROC) analysis was performed to identify the optimal cutoff values (including its validity) of WHtR to detect MetS and to detect $\geq 2$ MetD.

To assess the relationship of these cutoff values with other obesity related indices, the following 
analysis was done. Within different ages and within each group of normal and overweight/ obese children, metabolic derangements were compared using $t$ test between children categorised according to newly developed WHtR cut-off and according to other international cut-offs. The validity of newly developed WHtR cut-off for detecting individual metabolic derangements was further compared with the validity of international cut-offs.

\section{RESULTS}

The total study population was 920 (547 boys) children. One hundred and fifty three (16.6\%) children were overweight/obese while 256 (27.8\%) were wasted. The distribution of metabolic derangements in the study population is published elsewhere [1]. Based on ROC analysis, the WHtR cutoff value to diagnose MetS was 0.51 (sensitivity-1.00; specificity-0.83) in boys and 0.49 (sensitivity-0.83; specificity-0.83) in girls (Figure 1). To detect $\geq 2$ MetD, the WHtR cutoff value was 0.42 (sensitivity-0.6; specificity-0.62) in boys and 0.45 (sensitivity-0.62; specificity-0.62) in girls (Figure 2).

Figure 1: ROC curve to determine WHtR associated with Metabolic syndrome in 5-15 year old girls and boys.



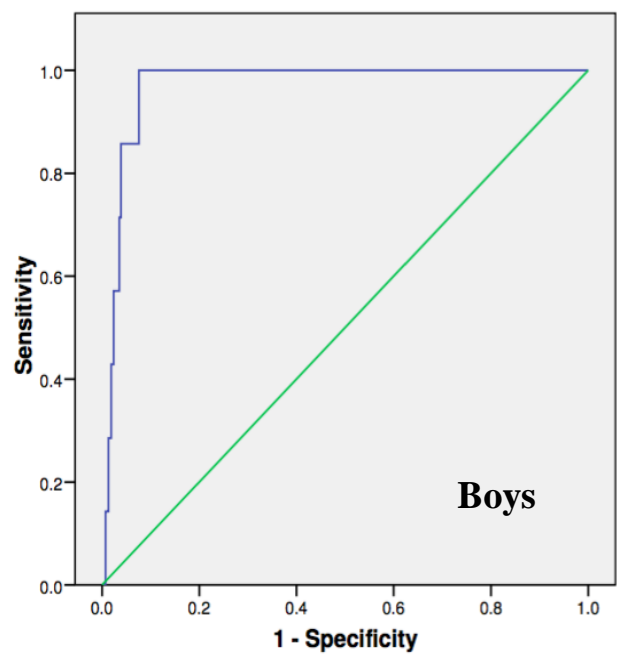

\begin{tabular}{|l|l|l|l|l|l|}
\hline & Area & $\begin{array}{l}\text { Std } \\
\text { Error }\end{array}$ & $\begin{array}{l}\text { Asymptotic } \\
\text { Sig }\end{array}$ & \multicolumn{2}{|l|}{$\begin{array}{l}\text { Asymptotic 95\% } \\
\text { Confidence Interval }\end{array}$} \\
\hline & & & & $\begin{array}{l}\text { Lower } \\
\text { Bound }\end{array}$ & $\begin{array}{l}\text { Upper } \\
\text { Bound }\end{array}$ \\
\hline Male & 0.97 & 0.010 & 0.001 & 0.95 & 0.989 \\
\hline Female & 0.892 & 0.033 & 0.001 & 0.828 & 0.957 \\
\hline
\end{tabular}

Figure 2: ROC to determine WHtR associated with $\geq 2$ Metabolic derangements in 5-15 year old girls and boys.

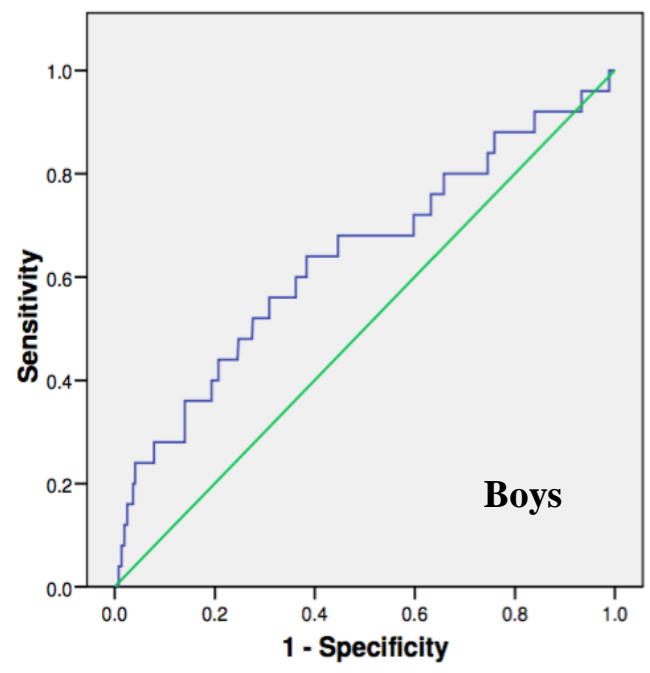




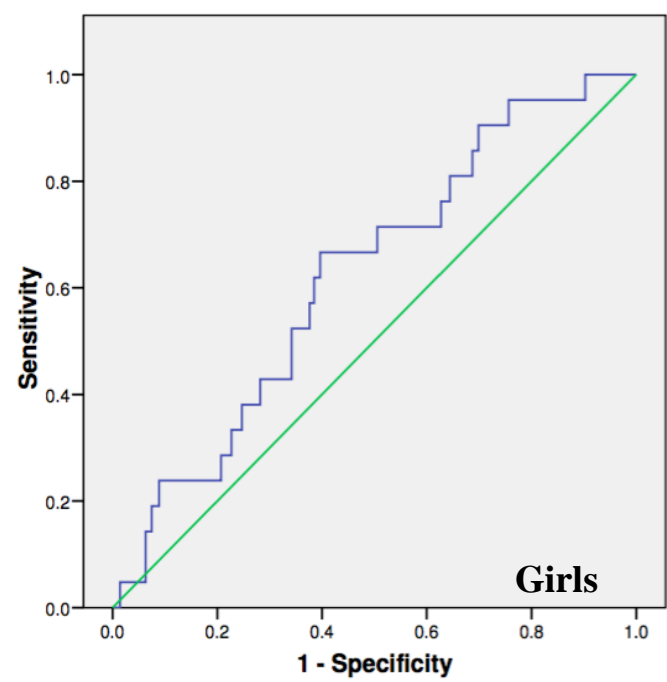

\begin{tabular}{|l|l|l|l|l|l|}
\hline & Area & $\begin{array}{c}\text { Std } \\
\text { Error }\end{array}$ & $\begin{array}{c}\text { Asymptotic } \\
\text { Sig }\end{array}$ & \multicolumn{2}{|c|}{$\begin{array}{c}\text { Asymptotic 95\% } \\
\text { Confidence } \\
\text { Interval }\end{array}$} \\
\hline Male & 0.637 & 0.063 & 0.020 & 0.513 & 0.761 \\
\hline Female & 0.622 & 0.058 & 0.059 & 0.509 & 0.736 \\
\hline
\end{tabular}

The sample was categorised into normal weight (BMI between -2SD and +1SD) and overweight/obese (BMI >+1SD) (Table 1). Each group was further categorised according to two different WHtR categories (one based on the internationally accepted 0.5 cutoff value and the other based on 0.45 that was defined to detect $\geq 2$ MetD in the current study). There was no difference in the age across these groups. BMI was significantly higher in the groups of higher WHtR except the 0.45 cutoff groups in the overweight group. Percentage FM, WC and WHtR showed significantly higher levels in the groups of higher WHtR in both overweight and normal groups. HDL-cholesterol was significantly low in the higher WHtR group in the overweight group. Cholesterol, Triglyceride and LDL-cholesterol showed higher values in the groups of higher WHtR and in some it was significant (shaded background in the table).

Table 2 shows the sensitivity and specificity of different WHtR cutoff values as well as BMI +1SD cutoff value in detecting adverse metabolic derangements. In detecting children with elevated blood pressure, cholesterol, triglyceride, LDL-C, low HDL-C or at least 2 or more metabolic derangements, WHtR $\geq 0.45$ had a higher sensitivity compared to WHtR $\geq 0.5$ (Table 2). When WHtR $\geq 0.45$ was compared with BMI $+1 \mathrm{SD}$ cutoff, the former had a higher sensitivity. Although the specificity of WHtR $\geq 0.45$ was lower compared to the other two cutoff values, it was still higher than $73 \%$ for all assessed metabolic derangements. In recognizing MetS, WHtR showed 100\% sensitivity with $75 \%$ specificity. In the detection of elevated ALT, all indices showed low sensitivity, but WhtR $>0.45$ showed the highest sensitivity $(40 \%)$. None of the indices showed promise in detecting dysglycaemia.

Table 3 shows the mean WHtR for each age group. In both boys and girls, the mean value did not show significant variation. The proportion who had higher \% Fat Mass was 14\% among boys compared to $31 \%$ in girls. Among boys, the proportion detected as being at risk for overweight/obese was similar to the proportion detected by BMI +1SD cutoff. WHtR $>0.5$ cutoff slightly underestimated the number of individuals to have a higher percentage fat mass while $>0.45$ cutoff value overestimated. Among females, the BMI +1SD cutoff value and $\mathrm{WHtR}>0.5$ underestimated the number of individuals having high body fat mass, while $>0.45$ cutoff over estimated it.

\section{DISCUSSION}

Similar to increase of childhood obesity, high rates of central obesity, denoted by increased WHtR, have been observed during last few decades. WHtR is more closely linked to childhood morbidity than BMI [16]. It can be used as a measure of obesity related morbidity in children as well as in adults. The simple public health message, 'keep your waist circumference to less than half your height' is valid for both adults and children of both sexes across all ages [16].

In 5-17 year old children in the Bogalusa heart study, BMI-for-age and waist-to-height ratio did not differ in their ability to identify children with adverse metabolic risk. Although WHtR is a simple tool much preferred in day to day clinical and epidemiological practice, it needs additional longitudinal data as it has not been adequately studied for understanding its relation to disease [17]. 
Table 1: Distribution of demographic and metabolic parameters in normal, and overweight/obese children categorized according to two different WHtR cutoff values in each group.

\begin{tabular}{|c|c|c|c|c|c|c|c|c|}
\hline & \multicolumn{4}{|c|}{ Normal (BMI SD -2SD - +1) } & \multicolumn{4}{|c|}{ Overweight/obese (BMI SD >+1) } \\
\hline & $\begin{array}{r}\text { WHtR }<0.5 \\
(n=507)\end{array}$ & $\begin{array}{r}\text { WHtR } \geq 0.5 \\
(n=14)\end{array}$ & $\begin{array}{c}\text { WHtR }<0.45 \\
(n=431)\end{array}$ & $\begin{array}{c}\text { WHtR } \geq 0.45 \\
(n=90)\end{array}$ & WhtR $<0.5(n=42)$ & $\begin{array}{c}\text { WHtR } \geq 0.5 \\
(n=111)\end{array}$ & $\begin{array}{c}\text { WHtR< } \\
0.45 \\
(n=7) \\
\end{array}$ & $\begin{array}{c}\text { WHtR } \geq 0.45 \\
(n=146)\end{array}$ \\
\hline Age & $10.0(2.7)$ & $10.5(2.7)$ & $10.1(2.7)$ & $9.8(2.9)$ & $10.1(2.3)$ & $10.5(2.4)$ & $12.5(2.6)$ & $10.28(2.3)$ \\
\hline BMI & $15.6(1.9)$ & $18.1(1.9)$ & $15.4(1.6)$ & $17.4(2.2)$ & $20.2(2.2)$ & $23.2(3.1)$ & $22.5(3.1)$ & $22.4(3.2)$ \\
\hline$\% \mathbf{F M}$ & $19.2(6.6)$ & $31.6(8.6)$ & $18.1(5.8)$ & $26.1(7.8)$ & $29.9(7.7)$ & $38.1(8.6)$ & $21.9(13.1)$ & $36.6(8.3)$ \\
\hline $\mathbf{W C}$ & $57.2(6.7)$ & $70.0(7.1)$ & $56.3(6.0)$ & $63.56(8.39)$ & $65.4(6.8)$ & $78.3(8.8)$ & $61.6(11.5)$ & $75.3(9.7)$ \\
\hline WHtR & $0.42(0.03)$ & $0.51(0.02)$ & $0.41(0.02)$ & $0.48(0.2)$ & $0.47(0.02)$ & $0.54(0.04)$ & $0.43(0.29)$ & $0.53(0.04)$ \\
\hline SBP & $97.6(9.5)$ & $95.9(9.8)$ & $97.7(11.8)$ & $96.3(13.3)$ & $106.6(10.7)$ & $105.5(14.1)$ & $111.4(15.7)$ & $105.5(13.1)$ \\
\hline DBP & $60.1(9.5)$ & $59.9(7.9)$ & $60.2(9.2)$ & $59.35(10.4)$ & $66.6(7.8)$ & $65.5(9.5)$ & $68.3(10.3)$ & $65.7(8.9)$ \\
\hline FBS & $80.5(8.8)$ & $80.9(10.3)$ & $80.6(8.9)$ & $80.1(8.8)$ & $83.1(9.4)$ & $80.8(8.7)$ & $85.2(11.9)$ & $81.2(16.0)$ \\
\hline RBS & $88.6(16.3)$ & $86.4(21.7)$ & $88.4(16.2)$ & $89.5(17.6)$ & $94.4(15.4)$ & $97.4(16.4)$ & 91.7 (18.6) & $96.8(16.0)$ \\
\hline Cholesterol & $164.0(33.5)$ & $171.7(42.4)$ & $161.9(33.7)$ & $175.3(32.2)$ & $173.1(42.4)$ & $173.3(34.9)$ & $156.8(50.1)$ & $174.0(36.3)$ \\
\hline Triglyceride & $75.8(32.4)$ & $82.4(29.4)$ & $75.2(32.5)$ & $79.6(31.6)$ & $87.5(36.5)$ & 94.3 (41.9) & $74.03(29.2)$ & $93.3(40.9)$ \\
\hline HDL & $47.9(16.0)$ & $42.6(14.7)$ & $47.8(16.2)$ & $47.7(15.0)$ & $47.5(14.05)$ & 43.8 (13.7) & $57.2(22.1)$ & $44.2(13.2)$ \\
\hline LDL & $100.8(34.8)$ & $112.7(40.7)$ & $98.9(34.8)$ & 111.7 (33.9) & $107.0(43.4)$ & $110.7(34.9)$ & $84.8(50.7)$ & $110.9(36.3)$ \\
\hline ALT & 13.4 (13.6) & $16.02(13.6)$ & $12.7(13.4)$ & $16.7(14.3)$ & $17.8(19.3)$ & 16.7 (15.6) & $20.6(23.3)$ & $16.8(16.3)$ \\
\hline
\end{tabular}

${ }^{1}$ Underweight children were excluded from analysis. Shaded area denotes statistically significant difference between the two categories 
Table 2: Validity measures on detecting abnormal metabolic parameters in the study group by different anthropometric (Waist to height ratio and Body Mass Index) cutoff values.

\begin{tabular}{|c|c|c|c|c|c|c|c|}
\hline \multirow{3}{*}{$\begin{array}{c}\text { Abnormal } \\
\text { metabolic profile }\end{array}$} & \multirow[t]{3}{*}{ No. } & \multicolumn{6}{|c|}{ No with abnormal metabolic profile detected } \\
\hline & & \multicolumn{2}{|c|}{ byWHtR $>0.5$} & \multicolumn{2}{|c|}{ byWHtR>0.45 } & \multicolumn{2}{|c|}{ by BMI >1SD } \\
\hline & & Sensitivity & Specificity & Sensitivity & Specificity & Sensitivity & Specificity \\
\hline Hypertension $^{1}$ & 59 & $19(32.2 \%)$ & $754(87.7 \%)$ & $32(54.2 \%)$ & $652(87.7 \%)$ & $26(44.1 \%)$ & $733(85.2 \%)$ \\
\hline Dysgkycaemia $^{2}$ & 14 & $0(0.0 \%)$ & $775(86.1 \%)$ & $2(14.3 \%)$ & $664(73.8 \%)$ & $2(14.3 \%)$ & $749(83.2 \%)$ \\
\hline Cholesterol (>200mg/dl) & 139 & $30(21.6 \%)$ & $684(87.8 \%)$ & $55(39.6 \%)$ & $594(76.3 \%)$ & $38(27.3 \%)$ & $664(85.2 \%)$ \\
\hline $\begin{array}{l}\text { Triglyceride } \\
(>150 \mathrm{mg} / \mathrm{dl})\end{array}$ & 36 & $12(33.3 \%)$ & $768(87.2 \%)$ & $18(50.0 \%)$ & $659(74.8 \%)$ & $14(38.9 \%)$ & $742(84.2 \%)$ \\
\hline $\mathrm{HDL}(<40 \mathrm{mg} / \mathrm{dl})$ & 337 & $61(18.1 \%)$ & $515(89.1 \%)$ & $101(30.0 \%)$ & $441(76.3 \%)$ & $66(19.6 \%)$ & $493(85.3 \%)$ \\
\hline LDL (>130mg/dl) & 176 & $36(20.5 \%)$ & $648(88.0 \%)$ & $68(38.6 \%)$ & $566(76.9 \%)$ & $45(25.6 \%)$ & $630(85.6 \%)$ \\
\hline ALT (>40IU/L) & 65 & $12(18.5 \%)$ & $730(86.6 \%)$ & $26(40.0 \%)$ & $630(74.7 \%)$ & $16(24.6 \%)$ & $707(83.9 \%)$ \\
\hline Metabolic syndrome & 14 & $12(85.7 \%)$ & $793(87.5 \%)$ & $14(100.0 \%)$ & $680(75.1 \%)$ & $13(92.9 \%)$ & $766(84.5 \%)$ \\
\hline Metabolic derangements & 46 & $12(26.1 \%)$ & $761(87.1 \%)$ & $19(41.3 \%)$ & $653(74.7 \%)$ & $16(34.8 \%)$ & $737(84.3 \%)$ \\
\hline Elevated Fat content ${ }^{3}$ & 192 & $111(57.8 \%)$ & $714(98.1 \%)$ & $166(86.5 \%)$ & $654(89.8 \%)$ & $133(69.3 \%)$ & $708(97.3 \%)$ \\
\hline
\end{tabular}

${ }^{1}$ Systolic blood pressure and/or diastolic blood pressure $>2 \mathrm{SD} ;{ }^{2}$ Fasting blood sugar $>100$ and/or random blood sugar $>140 \mathrm{mg} / \mathrm{dl} ;{ }^{3}$ cutoff for elevated fat content was considered $>28.6 \%$ for boys and $>33.7 \%$ for girls. 
Table 3: Mean (SD) WHtR and the number of children with an elevated \%FM detected by different BMI and WHtR indices in children of each different age group of each gender

\begin{tabular}{|c|c|c|c|c|c|c|c|c|c|c|c|c|}
\hline \multirow{2}{*}{$\begin{array}{c}\text { Ag } \\
\text { e }\end{array}$} & \multicolumn{6}{|c|}{ Boys } & \multicolumn{6}{|c|}{ Girls } \\
\hline & No. & $\begin{array}{l}\text { Mean } \\
\text { WHtR }\end{array}$ & $\begin{array}{l}\% \mathrm{FM} \\
>28.6\end{array}$ & $\begin{array}{l}\text { BMI } \\
>1 S D\end{array}$ & $\begin{array}{c}\text { WHtR } \\
>0.5\end{array}$ & $\begin{array}{c}\text { WHtR }>0.4 \\
5\end{array}$ & No & $\begin{array}{c}\text { Mean } \\
\text { WHtR }\end{array}$ & $\begin{array}{l}\% \mathrm{FM} \\
>33.7\end{array}$ & $\begin{array}{c}\text { BMI } \\
>1 S D\end{array}$ & $\begin{array}{c}\text { WHtR } \\
>0.5\end{array}$ & $\begin{array}{l}\text { WHtR } \\
>0.45\end{array}$ \\
\hline 5 & 23 & $0.45(0.05)$ & $2(8.7 \%)$ & $2(8.7 \%)$ & $3(13.0 \%)$ & $7(30.4 \%)$ & 23 & $0.45(0.02)$ & $2(8.7 \%)$ & $0(0.0 \%)$ & $0(0.0 \%)$ & $9(39.1 \%)$ \\
\hline 6 & 50 & $0.42(0.03)$ & $2(4.0 \%)$ & $2(4.0 \%)$ & $2(4.0 \%)$ & $6(12.0 \%)$ & 24 & $0.44(0.04)$ & $3(12.5 \%)$ & $2(8.3 \%)$ & $1(4.2 \%)$ & $7(29.2 \%)$ \\
\hline 7 & 67 & $0.44(0.05)$ & $13(19.4 \%)$ & $10(14.9 \%)$ & $9(13.4 \%)$ & $13(19.4 \%)$ & 47 & $0.44(0.05)$ & $14(29.8 \%)$ & $10(21.3 \%)$ & $7(14.9 \%)$ & $17(36.2 \%)$ \\
\hline 8 & 53 & $0.43(0.05)$ & $7(13.2 \%)$ & $9(17.0 \%)$ & $6(11.3 \%)$ & $9(17.0 \%)$ & 47 & $0.45(0.06)$ & $15(31.9 \%)$ & $15(31.9 \%)$ & $10(21.3 \%)$ & $21(44.7 \%)$ \\
\hline 9 & 65 & $0.43(0.05)$ & $9(13.8 \%)$ & $9(13.8 \%)$ & $7(10.8 \%)$ & $12(18.5 \%)$ & 56 & $0.46(0.06)$ & $23(41.1 \%)$ & $17(30.4 \%)$ & $13(23.2 \%)$ & $25(44.6 \%)$ \\
\hline 10 & 65 & $0.42(0.06)$ & $11(16.9 \%)$ & $10(15.4 \%)$ & $8(12.3 \%)$ & $14(21.5 \%)$ & 33 & $0.43(0.05)$ & $9(27.3 \%)$ & $6(18.2 \%)$ & $6(18.2 \%)$ & $8(24.2 \%)$ \\
\hline 11 & 57 & $0.44(0.06)$ & $13(22.8 \%)$ & $15(26.3 \%)$ & $10(17.5 \%)$ & $23(40.4 \%)$ & 35 & $0.43(0.06)$ & $11(31.4 \%)$ & $7(20.0 \%)$ & $7(20.0 \%)$ & $11(31.4 \%)$ \\
\hline 12 & 67 & $0.42(0.06)$ & $11(16.4 \%)$ & $9(13.4 \%)$ & $10(14.9 \%)$ & $15(22.4 \%)$ & 34 & $0.42(0.05)$ & $9(26.5 \%)$ & $5(14.7 \%)$ & $5(14.7 \%)$ & $7(20.6 \%)$ \\
\hline 13 & 46 & $0.41(0.05)$ & $5(10.9 \%)$ & $5(10.9 \%)$ & $3(6.5 \%)$ & $7(15.2 \%)$ & 34 & $0.43(0.07)$ & $11(32.4 \%)$ & $7(20.6 \%)$ & $6(17.6 \%)$ & $8(23.5 \%)$ \\
\hline 14 & 37 & $0.4(0.05)$ & $2(8.7 \%)$ & $2(5.4 \%)$ & $2(5.4 \%)$ & $4(10.8 \%)$ & 28 & $0.46(0.08)$ & $12(42.9 \%)$ & $7(25.0 \%)$ & $8(28.6 \%)$ & $12(42.9 \%)$ \\
\hline 15 & 17 & $0.4(0.04)$ & $1(5.9 \%)$ & $2(11.8 \%)$ & $1(5.9 \%)$ & $2(11.8 \%)$ & 8 & $0.43(0.03)$ & $4(50.0 \%)$ & $0(0.0 \%)$ & $0(0.0 \%)$ & $1(12.5 \%)$ \\
\hline 16 & 0 & $0(0.0 \%)$ & $0(0.0 \%)$ & $0(0.0 \%)$ & $0(0.0 \%)$ & $0(0.0 \%)$ & 4 & $0.47(0.07)$ & $3(75.0 \%)$ & $0(0.0 \%)$ & $1(25.0 \%)$ & $2(50.0 \%)$ \\
\hline All & 547 & $0.43(0.05)$ & $7613.9 \%)$ & $75(13.7 \%)$ & $61(11.2 \%)$ & $112(20.5 \%)$ & 373 & $0.44(0.06)$ & $116(31.1 \%)$ & $78(20.9 \%)$ & $64(17.2 \%)$ & $128(34.3 \%)$ \\
\hline
\end{tabular}


Data from five Canadian national surveys involving 5-18 year old children revealed that increased WHtR was significantly associated with increased cardiometabolic risk in overweight and obese subjects, with the greatest associations observed in the obese population [18]. This study showed that although obese or overweight, their cardionmetabolic risk was closer to non obese/overweight (normal BMI) children if their WHtR was $<0.5$. Therefore WHtR was considered a better tool for cardiometbolic risk screening and those with an elevated WHtR should undergo further cardiometabolic risk assessment.

Cutoff values developed in our study to detect MetS in children was same as the international cutoffs described in literature, which is 0.5 [16]. However, MetS in children is a condition that occurs as a result of having an adverse metabolic state for a long period of time, and therefore its ability to reverse is low. Effects of MetS on long term health are quite high. Therefore, detecting the adverse metabolic profile at an early stage of its development is crucial for improving long term health. We tried to derive cutoff values that would detect at least two metabolic derangements in this population. In boys and girls, the values were 0.42 and 0.45 respectively, with more than $60 \%$ sensitivity and specificity in both groups, which could be considered as a satisfactory cutoff value. However, for practical purpose, the value was rounded to 0.45 irrespective of sex and age.

WHtR cutoff value of 0.45 showed better sensitivity and specificity in detecting abnormal metabolic profiles than a WHtR cutoff value of 0.5 and BMI cutoff value of $+1 \mathrm{SD}$. Even within the normal BMI category, individuals with higher WHtR were seen to have a more adverse metabolic profile compared to those with lower WHtR. A similar association was also seen within the BMI $>+1$ SD category. This shows that WHtR is more effective in detecting an adverse metabolic profile than BMI. BMI looks at the entire body mass standardized to height squared, whereas WHtR looks at the waist circumference, which is the direct risk factor for the origin of NCD's later in life, standardized to height. Therefore, WHtR could be considered a more direct measure of the 'risk factor'.
WHtR was also able to detect more individuals with adverse fat accumulation in the body. Both international cutoff value of WHtR and +1SD BMI value showed some similarity. However, the 0.45 cutoff of WHtR improved the detection of central obesity as detected using fat mass of the body. This shows that ethnic specific cutoff values should be defined not only for BMI but also for other indices such as WHtR.

If WHtR is to be used as a screening tool for assessing elevated fat content of the body, the international cutoff, which is 0.5 , under detects cases of obesity, while the cutoff value which is defined by us, which is 0.45 , overestimates it only by a small number.

Being an index derived using two simple measurements, WHtR can be very useful in early detection of high percentage body fat mass and adverse metabolic profiles. Although it may overestimate slightly, it would fulfill the ideal characteristics of a screening tool.

\section{CONCLUSIONS}

WHtR is a simple index that is useful for detecting obesity as well as adverse cardiometabolic profile. However, population specific cutoff values need to be derived to improve its validity. WHtR cutoff of 0.45 had the best sensitivity and specificity, thus it is considered a better index to screen for overweight/obesity than BMI, in this cohort of Sri Lankan children.

\section{ACKNOWLEDGEMENTS}

We are grateful to all children and their parents for participating in this study. Ms Amara $S$ de $S$ Wijerathna and Ms. A. U. A. Gunawardhana of the Reproductive Biology Laboratory, Department of Obstetrics and Gynaecology and Mr. S.D.D. Dissanayake of the Department of Paediatrics, University of Colombo in analyzing the blood samples.

This study was carried out through an educational grant from Anchor institute, to the University of Colombo. 


\section{REFERENCE}

1. Wickramasinghe VP, Arambepola C, Bandara P, Abeysekera M, Kuruppu S, Dilshan P, et al. Distribution of obesity-related metabolic markers among 5-15 year old children from an urban area of Sri Lanka. Ann Hum Biol. 2013;40(2):168-74.

2. Savva SC, Tornaritis M, Savva ME, Kourides Y, Panagi A, Silikiotou N, et al. Waist circumference and waist-to-height ratio are better predictors of cardiovascular disease risk factors in children than body mass index. Int $\mathbf{J}$ ObesRelatMetabDisord. 2000;24(11):1453-8.

3. Wickramasinghe VP, Lamabadusuriya SP, Cleghorn GJ, Davies PS. Validity of currently used cutoff values of body mass index as a measure of obesity in Sri Lankan children. Ceylon Med J. 2009;54(4):114-9.

4. Wickramasinghe VP, Arambepola C, Bandara DM, Abeysekera M, Kuruppu S, Dilshan P, et al. Validity of newly-developed BMI and waist cut-off values for Sri Lankan children. Ann Hum Biol. 2013;40(3):280-5.

5. Jayawardana R, Ranasinghe $\mathrm{P}$, Sheriff $\mathrm{MH}$, Matthews DR, Katulanda P. Waist to height ratio: a better anthropometric marker of diabetes and cardio-metabolic risks in South Asian adults. Diabetes Res ClinPract. 2013;99(3):292-9.

6. Higgins M, Kannel W, Garrison R, Pinsky J, Stokes J, 3rd. Hazards of obesity--the Framingham experience. Acta Med Scand Suppl. 1988;723:23-36.

7. Hsieh SD, Muto T. The superiority of waistto-height ratio as an anthropometric index to evaluate clustering of coronary risk factors among non-obese men and women. Prev Med. 2005;40(2):216-20.

8. Ashwell M, Hsieh SD. Six reasons why the waist-to-height ratio is a rapid and effective global indicator for health risks of obesity and how its use could simplify the international public health message on obesity. Int J Food SciNutr. 2005;56(5):303-7.

9. Kuczmarski RJ, Ogden CL, Grummer-Strawn LM, Flegal KM, Guo SS, Wei R, et al. CDC growth charts: United States. Adv Data. 2000(314):1-27.
10. Lohman TG, Assessment of body composition in children. Pediatric Exercise Science. 1989;1:12.

11. WHO. WHO Growth Spurttandards. 2007.

12. Wickramasinghe VP, Arambepola C, Bandara P, Abeysekera M, Kuruppu S, Dilshan P, et al. Defining Obesity Using a Biological End Point in Sri Lankan Children. Indian J Pediatr. 2017;84(2):117-23.

13. McCarthy HD, Jarrett KV, Crawley HF. The development of waist circumference percentiles in British children aged 5.0-16.9 y. Eur J ClinNutr. 2001;55(10):902-7.

14. Zimmet P AK, Kaufman F, Tajima N, Silink M, Arslanian S. . The metabolic syndrome in children and adolescents - an IDF consensus report. Pediatr Diabetes. 2007;8:8.

15. Jackson LV, Thalanga, N.K.S., Cole, T.J. , . Blood pressure centriles for Great Britain., 2007. 29: p. 5. Archieves of Diseases in Childhood. 2007;29:5.

16. McCarthy HD, Ashwell M. A study of central fatness using waist-to-height ratios in UK children and adolescents over two decades supports the simple message--'keep your waist circumference to less than half your height'. Int J Obes (Lond). 2006;30(6):988-92.

17. Freedman DS, Kahn HS, Mei Z, GrummerStrawn LM, Dietz WH, Srinivasan SR, et al. Relation of body mass index and waist-toheight ratio to cardiovascular disease risk factors in children and adolescents: the Bogalusa Heart Study. Am J ClinNutr. 2007;86(1):33-40.

18. Khoury M, Manlhiot C, McCrindle BW. Role of the waist/height ratio in the cardiometabolic risk assessment of children classified by body mass index. J Am CollCardiol. 2013;62(8):742-51. 